two identical looking fixes the M.P.P. changes according to the azimuths of the observations and what different reliability the two fixes can be given (Figs. 5, 6).

Apart from the actual distance between the two M.P.P.'s-which could be some miles-the method of bisectors shows that the case in Fig. 5 is quite a reliable fix as there is only a systematic error, whereas the case in Fig. 6 is less reliable because there is a random error, or a blunder: two of the lines-as seen from the M.P.P.- -are pointing outwards and the other two inwards.

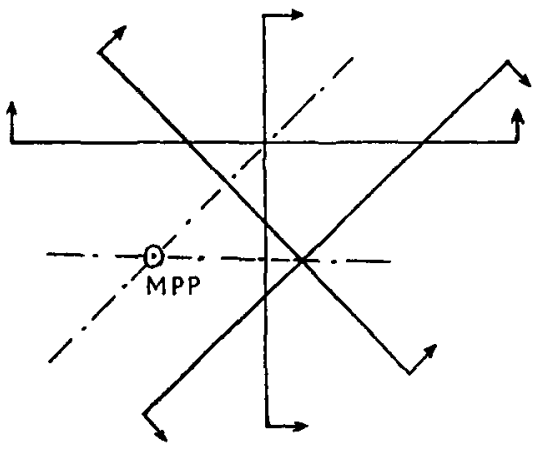

Fig. 5. Az $0^{\circ}, 90^{\circ}, 45^{\circ}, 135^{\circ}$.

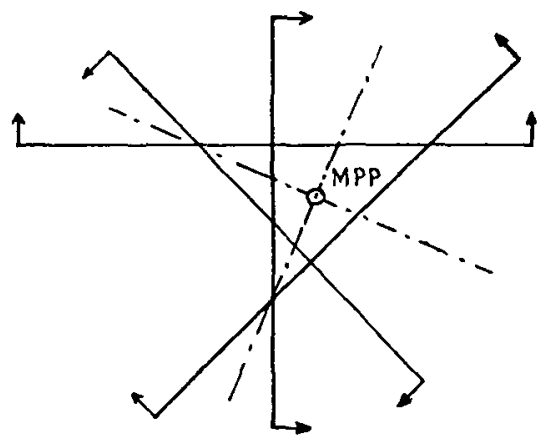

Fig. 6. $A z 0^{\circ}, 90^{\circ}, 225^{\circ}, 315^{\circ}$.

Mr. Parker's comment ends by saying: ' . . . there is no great gain in choosing the stars to be roughly $90^{\circ}$ apart, and Mr. Davies' method appears to be quite as good as those described by Commander Bini'.

Now if we speak of methods I cannot agree because what Mr. Davies proposes, i.e. using three stars to get a cocked hat and a fourth one to indicate the likelihood of the M.P.P. being inside or outside it cannot be called a method for the reasons already pointed out in my comment on Mr. Davies' note (and principally because it will never be able to establish which is the fourth line).

However, if, as I believe, Mr. Parker means that it is not necessary to use stars $90^{\circ}$ apart and that also if they are observed in a different way a good M.P.P. can be obtained by using the bisectors, then I again agree with Mr. Parker. In fact the method of bisectors indicates the practice of taking stars $90^{\circ}$ apart as the best way of sight taking (with four stars), but it can be applied in any case.

\title{
Dead Reckoning Error over the North Atlantic
}

Mr. P. G. Powell, Chief Navigating Officer of Trans-Canada Airlines, has allowed publication of the following note, originally presented at an I.A.T.A. meeting.

1. Introduction. Air traffic controllers separate aircraft on the North Atlantic with reference to dead reckoning (D.R.) positions of aircraft. Two such D.R. positions are transmitted to a.t.c. regularly from each aircraft, one usually 10 to 30 minutes following a fix, the other one hour's run farther ahead. The accuracy of these positions is important, since it has a direct bearing on horizontal separation standards and optimum time between position reports.

D.R. accuracy has been investigated previously on a theoretical basis. How- 
ever, the assumptions made in such an investigation throw doubt on the results. Consequently, an attempt has been made hereunder to examine errors in D.R. actually experienced in flight between Canada and the United Kingdom.

An examination was made of navigators' logs and charts, and 'back plotting' and other methods employed to correct the positions of plotted fixes as nearly as possible. It is felt that any small remaining error would be inconsequential. 452 D.R. positions, each for the time of a corrected fix, were considered. The error (in n.m.) in each was measured and the time from the start of the D.R. plot (time between fixes) noted. In addition, the wind velocity estimated by the navigator for use in each D.R. plot was compared with the true wind as calculated between pairs of corrected fixes. Errors in mid-Atlantic were compared with those found in good Loran coverage on either side of the ocean.

Loran was the most used navigation aid, and in most cases gave good position lines throughout each flight. This was supplemented by Consol in the eastern Atlantic, and either supplemented or replaced by celestial in mid-Atlantic. Most fixes were plotted from at least three position lines. Little use was made of radio bearings or weather ships. The radio altimeter was used primarily to measure beam-wind component and so, in conjunction with the air plot, to calculate more accurate winds. Using found winds, measured pressure surface heights, intercepted AIREP messages and other information, the navigator reconstructed the upper-air chart, making adjustments with each observation. From this he estimated the wind for the next hour, and used this in calculating D.R. position. Pressure pattern procedures were followed; no attempt has been made to follow a defined track.

Since procedures vary with different airlines, the findings listed below can only be considered to apply to Trans-Canada Airlines. However, the figures are readily available in most airlines. It is suggested that, if similar figures were collected from different airlines, a more accurate picture would result.

2. Observations. Errors were random in direction. There was no tendency for error to occur more along than across track or vice versa. Nor was there any consistent observable correlation between direction of D.R. error and direction of fix error.

Although gross fix error influenced D.R. error, there was little noticeable correlation between the occurrence of the two. A gross fix error did not necessarily lead to a gross D.R. error. About as high a percentage of gross D.R. errors occurred under good fixing conditions as under poor.

Gross errors in D.R. were almost entirely due to gross errors in wind estimation, coupled with a long period between fixes. Gross errors in wind estimation usually result from unsuspected or under-estimated large wind changes.

Wind speed appears to have little bearing on probable error in estimated wind, where wind speed is less than 60 knots. Higher wind speeds than this appear to be conducive to large errors, as shown in Table I.

TABLE I

\begin{tabular}{cccc}
\hline $\begin{array}{c}\text { Wind speed } \\
\text { (kt.) }\end{array}$ & $\begin{array}{c}\text { R.M.S. error } \\
\text { (kt.) }\end{array}$ & $\begin{array}{c}\text { Errors (\%) } \\
30-40 \mathrm{kt} .\end{array}$ & $\begin{array}{c}\text { Errors over } \\
\text { 40 kt. (\%) }\end{array}$ \\
\hline $0-29$ & 20 & 9 & 5 \\
$30-59$ & $2 \mathrm{t}$ & 10 & 5 \\
$60-89$ & 28 & 23 & 10 \\
\hline
\end{tabular}


D.R. errors were greater in mid-Atlantic than in the eastern and western portions, as follows:

$\begin{array}{ccc}\text { Area } & \text { Mid-Atlantic } & \text { E. and W. Atlantic } \\ \text { r.m.s. error (n.m.) } & 24 & 18 \\ \text { \% errors over 30 n.m. } & 19 & 8\end{array}$

The difference in estimated wind error, however, is only 2 knots between the two areas.

R.m.s. wind error-mid-Atlantic 23 knots

R.m.s. wind error-E. and W. Atlantic 2 I knots

Consideration of the observation above suggests that the relatively large difference in D.R. errors between the two areas was due primarily to difference in average time between fixes. The average time between fixes in mid-Atlantic was 56 minutes; in E. and W. Atlantic it was 47 minutes. (In view of the nature of the fixing aids used, more time is normally spent in establishing an accurate fix in mid-Atlantic.)

A closer examination of D.R. error with time between fixes gives the results shown in Table II.

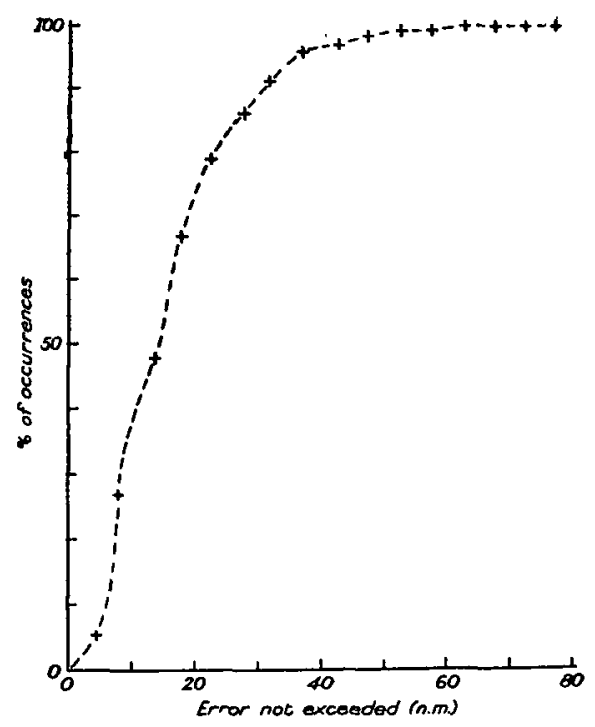

Fig. 1

These r.m.s. values were plotted against average time between fixes (Fig. I). The resulting curve was very nearly a straight line; i.e. for periods of time considered here, D.R. error varies directly as time between fixes (approximately). In fact, r.m.s. error in n.m. roughly equals time between fixes in minutes $\times 0^{\circ} 4$. A similar straight line was plotted through the maximum observed errors. Table III results: 
TABLE II

\begin{tabular}{ccccc}
\hline $\begin{array}{c}\text { Time between } \\
\text { fixes (min.) }\end{array}$ & $\begin{array}{c}\text { Average } \\
\text { duration (min.) }\end{array}$ & $\begin{array}{c}\text { No. of } \\
\text { observations }\end{array}$ & $\begin{array}{c}\text { R.M.S. error } \\
\text { in D.R. (n.m.) }\end{array}$ & $\begin{array}{c}\text { Errors of over } \\
\text { 30 n.m. (\%) }\end{array}$ \\
\hline $11-20$ & 20 & 1 & 10 & 0 \\
$21-30$ & 27 & 51 & 11 & 2 \\
$31-40$ & 35 & 65 & 14 & 2 \\
$41-50$ & 46 & 96 & 18 & 7 \\
$51-60$ & $56 \frac{1}{2}$ & 163 & 23 & 18 \\
$61-70$ & $64 \frac{1}{2}$ & 55 & 24 & 18 \\
$71-80$ & 74 & 14 & $30 \frac{1}{2}$ & 50 \\
$81-90$ & 85 & 4 & 23 & 25 \\
$90-100$ & 94 & 3 & 38 & 67 \\
\hline
\end{tabular}

TABle III

\begin{tabular}{ccc}
\hline $\begin{array}{c}\text { Time between } \\
\text { fixes (min.) }\end{array}$ & $\begin{array}{c}\text { R.M.S. error } \\
\text { in D.R. (n.m.) }\end{array}$ & $\begin{array}{c}\text { Maximum observed } \\
\text { error (n.m.) }\end{array}$ \\
\hline 20 & 9 & 25 \\
30 & 13 & 36 \\
40 & 16 & 44 \\
50 & 20 & 55 \\
60 & 24 & 66 \\
70 & 28 & 77 \\
80 & 32 & $88^{*}$ \\
90 & 36 & $99^{*}$ \\
100 & 40 & $110^{*}$ \\
\hline
\end{tabular}

Maximum observed error $=2.75 \times$ r.m.s. error.

*Not substantiated by observation.

R.m.s. vector error for all D.R. positions considered was $19 \cdot 8$ n.m. Frequency distribution of errors may be seen from the following:

$\begin{array}{ccc}\begin{array}{c}\text { D.R. Error } \\ (n . m .)\end{array} & \begin{array}{c}\text { No. } \\ \text { Observed }\end{array} & \begin{array}{c}\text { Observed } \\ (\%)\end{array} \\ 0-4 & 28 & 6 \cdot 2 \\ 5-9 & 98 & 21 \cdot 5 \\ 10-14 & 92 & 20 \cdot 4 \\ 15-19 & 83 & 18 \cdot 3 \\ 20-24 & 57 & 12 \cdot 6 \\ 25-29 & 30 & 6 \cdot 6 \\ 30-34 & 24 & 5 \cdot 3 \\ 35-39 & 24 & 5 \cdot 3 \\ 40-44 & 3 & 0 \cdot 7 \\ 45-49 & 8 & 1 \cdot 8 \\ 50-54 & 2 & 0 \cdot 4 \\ 55-59 & 0 & 0 \cdot 0 \\ 60-64 & 2 & 0 \cdot 4 \\ 65-69 & 0 & 0.0 \\ 70-74 & 0 & 0.0 \\ 75-79 & 1 & 0.2\end{array}$


Mr. C. S. Durst comments on this report:

The D.R. fixes in the T.C.A. report were made by using the best wind the navigator could determine from his previous leg and any other information he could pick up. Table IV (p. 97) in my paper* gives an approximation to the accuracy of such winds. From the table we see that the standard error in D.R. along (or across) track due to wind on a $250-\mathrm{mile} \mathrm{leg} \mathrm{at} 18,000 \mathrm{ft}$. is $\mathrm{I}_{3} \mathrm{kt}$. in winter, $9 \mathrm{kt}$. in summer; say, on average, i I kt. which corresponds to a standard vector error of $15 \frac{1}{2} \mathrm{kt}$. For an aircraft flying at $200 \mathrm{kt}$. and fixing every 56 minutes, i.e. every 185 miles, the corresponding r.m.s. vector error due to wind would be about 13 kt., and fixing every 47 minutes, 155 miles, the r.m.s. vector error would be about $12 \mathrm{kt}$.

On p. 99 of my paper I suggested that navigational errors appeared to be of the order of $16 \frac{1}{2} \mathrm{kt}$. to $13 \frac{1}{2} \mathrm{kt}$. and in these errors I included inaccuracy of calibration of the airspeed indicator, inaccuracy of the compass, and inaccuracy of fixing over one hour legs. Since the T.C.A. fixing was done with great care the estimate of navigational error might possibly be cut down to $12 \mathrm{kt}$. If then there were a navigational error of $12 \mathrm{kt}$., the total D.R. errors due to navigation and wind would be $17 \frac{1}{2}$ and $17 \mathrm{kt}$. for fixes every 56 minutes and every 47 minutes respectively. Thus it does not appear that the difference between the D.R. errors found by T.C.A. (para. 5) of 24 miles in mid-Atlantic and 18 miles in $E$. and W. Atlantic are due to the length of time between fixes. It is probable that the inaccuracy of the fixes in mid-Atlantic is greater than nearer the coasts. To get agreement with the 24 -mile error which T.C.A. find one would have to raise the navigational error to about $20 \mathrm{kt}$. in mid-Atlantic.

To check the figures in Table II of the T.C.A. report we will assume that there is a navigational error of $(a)$ I $2 \mathrm{kt}$., (b) $15 \mathrm{kt}$., (c) $20 \mathrm{kt}$.; that the vector standard wind error at $\mathrm{i} 8,000$ feet is $7 \frac{1}{2} \mathrm{kt}$ : for a leg of 50 miles (derived from Table IV of my paper), $10 \mathrm{kt}$. for a leg of 100 miles, $15 \frac{1}{2}$ for a leg of 250 miles and $23 \mathrm{kt}$. for a leg of 500 miles. If the speed of the aircraft is $200 \mathrm{kt}$. we then get the r.m.s. wind errors corresponding to various times shown in Table I.

TABLE I. EXPECTED R.M.S. VECTOR ERrorS FOR VARIOUS NAVIGATION ERRORS

\begin{tabular}{l|c|c|c|c|c|c|c|c|l}
\hline Duration (min.) & 20 & 27 & 35 & 46 & $56 \frac{1}{2}$ & $64 \frac{1}{2}$ & 74 & 85 & 94 \\
R.M.S. wind error (kt.) & $5 \frac{1}{2}$ & $9 \frac{1}{2}$ & $10 \frac{1}{2}$ & 12 & 13 & $13 \frac{1}{2}$ & 15 & 16 & $16 \frac{1}{2}$ \\
(a) Adjusted for I $2 \mathrm{kt}$. nav. error & 13 & 15 & 16 & 17 & $17 \frac{1}{2}$ & 18 & 19 & 20 & 20 \\
(b) Adjusted for I 5 kt. nav. error & 17 & 18 & 18 & 19 & 20 & 20 & $21 \frac{1}{2}$ & 22 & $22 \frac{1}{2}$ \\
(c) Adjusted for 20 kt. nav. error & 21 & 22 & $22 \frac{1}{2}$ & 23 & 24 & 24 & 25 & $25 \frac{1}{2}$ & 26 \\
R.M.S. Position error (n.m.) & & & & & & & & & \\
(a) Adjusted for I $2 \mathrm{kt.}$ nav. error & 4 & 7 & 9 & 13 & $16 \frac{1}{2}$ & $19 \frac{1}{2}$ & $23 \frac{1}{2}$ & $28 \frac{1}{2}$ & $31 \frac{1}{2}$ \\
(b) Adjusted for I 5 kt. nav. error & 6 & 8 & $10 \frac{1}{2}$ & 15 & 19 & $21 \frac{1}{2}$ & $26 \frac{1}{2}$ & 31 & $35 \frac{1}{2}$ \\
(c) Adjusted for 20 kt. nav. error & 7 & 10 & 13 & $17 \frac{1}{2}$ & 23 & 26 & 31 & 36 & 41 \\
R.M.S. Errors found by T.C.A. & 10 & 11 & 14 & 18 & 23 & 24 & $30 \frac{1}{2}$ & 23 & 38 \\
\hline
\end{tabular}

The agreement between the values in the last two rows suggests that the navigational errors (including errors in fixing) have a r.m.s. value of $20 \mathrm{kt}$.

The winds which were taken as true in the T.C.A. report were based on fixes which, from what has been said, were very likely in error. They were compared

*Durst, C. S. (1955). The accuracy of dead reckoning in the air. This Journal, 8, 91. 
with the winds estimated by the navigators from all sources at their disposal and, as has been said above, the probable r.m.s. of such winds is i $2 \mathrm{kt}$. for a run of $47 \mathrm{~min}$. and $13 \mathrm{kt}$. for a run of 56 minutes, say $12 \frac{1}{2}$ on average. When we compare this with the figures in Table I of the T.C.A. report we get the results shown in Table II.

TABLE II

\begin{tabular}{|c|c|c|c|}
\hline Wind Speed (kt.) & $0-29$ & $30-60$ & $60-89$ \\
\hline R.M.S. Error (kt.) & 20 & $2 I$ & 28 \\
\hline $\begin{array}{l}\text { Amount due to navigation (kt.) } \\
\text { If all were due to fixing and }\end{array}$ & $15 \frac{1}{2}$ & 17 & 25 \\
\hline $\left.\begin{array}{l}\text { runs were of } 43 \mathrm{~min} . \\
\text { r.m.s. error of individual } \\
\text { fixes would be }\end{array}\right\}$ & 8 n.m. & $8 \frac{1}{2}$ n.m. & I 3 n.m. \\
\hline
\end{tabular}

One can well understand that with strong winds, e.g. jet streams, the navigator's estimates of the probable wind will be less accurate than with light winds. However, this table gives the general magnitude of the navigation error and in the bottom line is the fixing error which would be needed to account for the navigation errors if the aircraft registered correctly its true airspeed (actually it does not). Again we find the navigational errors are considerable and it would seem that even with the best fixes that can be made at present and after careful post-flight consideration they cannot be relied on over the central Atlantic to be better than 5 or 10 n.m. (on occasion).

From the figures in Table III of the T.C.A. report we can get the r.m.s. vector position error of an aircraft which has got a fix (with a certain amount of error) and carried on by D.R. for various time intervals. They are shown in Table III below for a standard fixing error of $(a) 5$ miles, $(b) 10$ miles.

TABLE III. UnCERTAINTy OF POSITION (VECTOR) OF AN AIRCRAFT WHICH HAD FiXed ITS POSITION AND CARRIED ON BY D.R. FOR 30,60 AND $90 \mathrm{MIN}$.

(a) If its fixing error had been 5 miles and $(b)$ if its fixing error had been ro miles and the total error had been those given by T.C.A.

\begin{tabular}{cccc}
\hline $\begin{array}{c}\text { Time after fix } \\
\text { (min.) }\end{array}$ & $\begin{array}{c}\text { R.M.S. error } \\
\text { in fix }\end{array}$ & $\begin{array}{c}\text { R.M.S. error in D.R. } \\
\text { position }\end{array}$ & $\begin{array}{c}\text { R.M.S. error in D.R. } \\
\text { position off course }\end{array}$ \\
30 & $(a) 5$ miles & 12 miles & $8 \frac{1}{2}$ \\
& $(b) 10$ miles & 8 miles & $5 \frac{1}{2}$ \\
60 & $(a) 5$ miles & $23 \frac{1}{2}$ miles & $16 \frac{1}{2}$ \\
& $(b) 10$ miles & 22 miles & $15 \frac{1}{2}$ \\
90 & $(a) 5$ miles & $25 \frac{1}{2}$ miles & 24 \\
\hline
\end{tabular}

In the last column of Table III is given the r.m.s. error of the D.R. position off course which we may expect from the T.C.A. report. Figures of this type are of vital interest in calculating separations of air tracks such as I mentioned in p. 103 of my paper. I have made some fresh calculations on the basis of the figures given in my paper, but for aircraft of $200 \mathrm{kt}$. If the vector error in fixing 
is 10 miles I find the r.m.s. error in D.R. position off course would be $\mathrm{I} I \frac{1}{2}$ miles after half an hour, $15 \frac{1}{2}$ miles after one hour and $20 \frac{1}{2}$ miles after $1 \frac{1}{2}$ hours.

\title{
S-Diagrams for Solving Problems in Astronomical Navigation
}

\author{
from Professor W. M. Smart
}

1. THE method described in Schütte's paper ${ }^{1}$ is very ingenious and evidently simple in its application; it depends on solving two pairs of equations of identical forms (in terms of different variables) by simple inspection of diagrams constructed in accordance with the first pair of equations. In his paper the author states, with reference to a figure and without proof, the two pairs of equations referred to. It is obvious that the fourth of Schütte's equations (p. 310 ) is inconsistent with the figure and with the example he gives on the determination of altitude and 'azimuth' (pp. 3 1 2, 313). The trouble arises partly from misconception as to the use of the term azimuth. The method deserves a more detailed explanation of the derivation of the formulae and their application.

2. I shall use the diagram and the notation of Schütte's paper omitting, however, at first any reference to azimuth and replacing $G$ (denoting the heavenly body concerned) by the more familiar $X$. If $H$ is the hour angle, then in the figure $t=360^{\circ}-H$; if the heavenly body is 'west', then $t=H$. It is assumed that $t$, the declination $\delta$ and the latitude $\phi$ are all known; the object is to find the altitude (denoted here by $h$ ) and the true bearing.

From the east point $\mathrm{E}$ (Fig. 1) a great circle is drawn through $\mathrm{X}$ to meet the

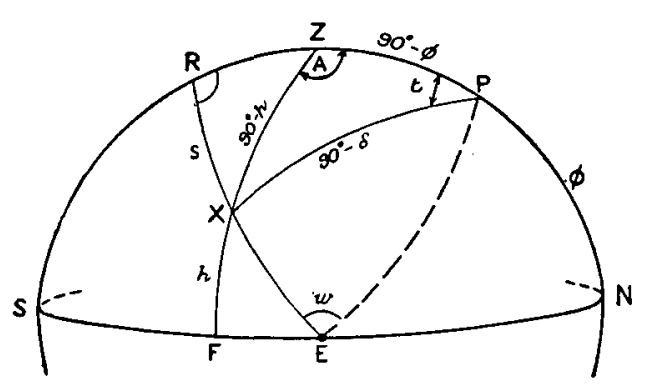

Fig. 1 observer's meridian PZS at R; since $E$ is a pole of $P Z S$, then angle $\mathrm{ZRX}$ is $90^{\circ}$. The arc $\mathrm{XR}$ is $s$ and $o<s<90^{\circ}$ always. In the figure the latitude is north (or positive); the declination may be north or south (that is, positive or negative). There are three principal cases according as $\mathrm{R}$ lies between $S$ and $Z$ (as in the figure), between $Z$ and $P$, and between $P$ and $N$.

The author designates the angle PER-or the arc PR-by $w$.

3. Case $I: R$ between $S$ and $Z$. Here, $o<t<90^{\circ} ; \mathrm{ZR}=\phi+w-90^{\circ} ; \delta$ is + or - . By means of the sine formula and the four-parts formula applied to the triangle PRX we obtain the pair of formulae which give $s$ and $w$ in terms of the known elements $t$ and $\delta$ :

$$
\begin{gathered}
\sin s=\sin t \cos \delta \\
\tan w=\cos t \cot \delta
\end{gathered}
$$

The curves $s=$ constant and $w=$ constant (each drawn on the same chart at intervals of $10^{\prime}$ ) are the curves on which the eventual solutions are based; they are constructed for the ranges $o \leqslant t \leqslant 90^{\circ}$ and $o \leqslant \delta \leqslant 90^{\circ}$. For convenience the 